\title{
BEBAN PENCEMARAN PADA KAWASAN PADAT PENDUDUK (STUDI KASUS SUNGAI BELIUNG)
}

\author{
Eka Kurnianti ${ }^{1}$, Nashrullah Chatib ${ }^{2}$, Robby Irsan ${ }^{1}$ \\ ${ }^{1}$ Program Studi Teknik Lingkungan, Universitas Tanjungpura, Pontianak \\ ${ }^{2}$ Program Studi Teknik Sipil, Universitas Tanjungpura, Pontianak \\ email: eka_kurnianti@yahoo.co.id
}

\begin{abstract}
ABSTRAK
Saluran drainase Sungai Beliung merupakan salah satu saluran primer yang dimanfaatkan untuk menampung dan mengalirkan air limpasan hujan dan limbah cair domestik secara tercampur. Peningkatan kepadatan penduduk menyebabkan meningkatnya volume limbah domestik dan beban pencemaran di saluran tersebut. Penelitian ini bertujuan untuk mengetahui kondisi kualitas air dan beban pencemaran yang terjadi dalam upaya pengendalian pencemaran air. Tahapan penelitian ini yaitu pengumpulan data primer berupa dimensi saluran (lebar dan kedalaman), luas penampang basah, kecepatan aliran, debit aliran, pengambilan sampel air dan perhitungan beban pencemaran. Pengambilan sampel kualitas air menggunakan metode grab sample saat kondisi pasang dan surut dengan parameter pencemar yaitu TSS, DO, BOD dan pH. Kualitas air di saluran drainase Sungai Beliung, berdasarkan hasil uji laboratorium untuk parameter pencemar yang mewakili, hanya memenuhi baku mutu untuk kelas IV menurut PP RI No. 82 tahun 2001 tentang Pengelolaan Kualitas Air dan Pengendalian Pencemaran Air yang peruntukannya untuk mengairi pertanaman. Kondisi ini menunjukkan bahwa air di saluran drainase Sungai Beliung tidak dapat digunakan untuk kebutuhan sehari-hari seperti air minum maupun aktifitas mandi,cuci,kakus. Beban pencemaran tertinggi di muara saluran (titik 5), berdasarkan parameter TSS saat pasang yaitu $1144 \mathrm{~kg} / \mathrm{hari}$, saat surut yaitu $1387 \mathrm{~kg} / \mathrm{hari}$ dan untuk parameter BOD saat pasang yaitu $543 \mathrm{~kg} / \mathrm{hari}$, saat surut yaitu $1065 \mathrm{~kg} / \mathrm{hari}$. Rata-rata beban pencemaran saat surut lebih tinggi dari pada saat pasang, dimana rata-rata beban pencemaran berdasarkan parameter TSS saat pasang yaitu $642 \mathrm{~kg} / \mathrm{hari}$, saat surut yaitu $437 \mathrm{~kg} / \mathrm{hari}$ dan rata-rata beban pencemaran berdasarkan parameter BOD, saat pasang yaitu $494 \mathrm{~kg} / \mathrm{hari}$, saat surut yaitu $304 \mathrm{~kg} / \mathrm{hari}$.
\end{abstract}

Kata kunci : Beban pencemaran, Saluran drainase, Sungai Beliung Pontianak Barat

\section{ABSTRACT}

The drainage channel of Sungai Beliung is one of the primary channels used to accommodate and drain the mixed from rain runoff and domestic liquid waste. Increasing population density also caused to increase volume of domestic waste and pollution load in Sungai Beliung channel. This study aims to determine the condition of the water quality and contamination load occurs in water pollution control efforts. Stages in this study is collecting primary data like of channel dimensions (width and depth), wet cross-sectional area, flow velocity, water discharge, sampling water and calculate of pollution load. Sampling of water was using grab sample method when tide and low tide with pollutant parameters are TSS, DO, BOD and $\mathrm{pH}$. Water quality in Sungai Beliung drainage, based on the test results in laboratory with pollutant parameters represents, only fulfill the quality standard for class IV according to Government Regulation Number 82 of 2001 on Management of Water Quality and Water Pollution Control that allotment to irrigate the crop. This condition shows that the water in Sungai Beliung drainage can't used for daily activities such as drinking or another activities like bathing, washing, toilet. The highest Pollution load in estuary (point 5), based on the TSS parameter when the tide was $1144 \mathrm{~kg} /$ day, at low tide was $1387 \mathrm{~kg} /$ day and BOD parameter during tide is $543 \mathrm{~kg} /$ day and when low tide is $1065 \mathrm{~kg} /$ day. The average pollution load when the low tide is higher than at tide, where the average was based on the TSS parameter of pollution load tide is $642 \mathrm{~kg} /$ day, while low tide is 437 $\mathrm{kg} /$ day and the average pollution load based on BOD parameter, during high tide is $494 \mathrm{~kg} /$ day, while during low tide is $304 \mathrm{~kg} /$ day.

Key words: Load pollution, drainage channels, Sungai Beliung in west Pontianak 


\section{PENDAHULUAN}

Saluran drainase Sungai Beliung merupakan salah satu drainase primer yang terdapat di Kecamatan Pontianak Barat, Kota Pontianak. Saluran drainase ini, memiliki panjang $\pm 1,8 \mathrm{~km}$ dan lebar antara 2-6 $\mathrm{m}$ yang bermuara ke Sungai Kapuas. Saluran drainase Sungai Beliung merupakan outlet dari saluran drainase sekunder dan tersier yang mengalirkan air limpasan hujan yang bercampur dengan air limbah buangan domestik rumah tangga untuk kawasan Kelurahan Sungai Jawi Luar dan Kelurahan Sungai Beliung, dengan kepadatan penduduk masing-masing yaitu $12.176 \mathrm{jiwa} / \mathrm{km}^{2}$ dan $8.629 \mathrm{jiwa} / \mathrm{km}^{2}$. Pertumbuhan jumlah penduduk yang semakin padat disekitar kawasan saluran drainase Sungai Beliung, mengakibatkan peningkatan volume air limbah domestik dan menambah beban pencemaran dari aktifitas sebagian masyarakat yang masih menggunakan saluran drainase tersebut untuk aktifitas mandi, cuci dan kakus (MCK).

Hasil pemantauan kualitas air tahun 2012 yang dilakukan oleh BLH Kota Pontianak untuk parameter BOD, yang menggambarkan pencemaran bahan organik dengan konsentrasi 7,64 $\mathrm{mg} / \mathrm{l}$ pada pemantauan pertama dan $7,14 \mathrm{mg} / \mathrm{l}$ pada pemantauan kedua. Berdasarkan baku mutu kualitas air yaitu PP RI No.82 tahun 2001 untuk kelas II maka konsentrasi BOD telah melebihi baku mutu. Hal ini menggambarkan tingginya bahan organik yang masuk kedalam saluran drainase Sungai Beliung sehingga dapat menyebabkan menurunnya kualitas air dan menimbulkan pencemaran pada perairan. Oleh karena itu perlu dilakukan kajian mengenai beban pencemaran pada saluran drainase Sungai Beliung agar dapat dilakukan tindak lanjut untuk pengendalian pencemaran air.

\section{METODOLOGI PENELITIAN}

Penelitian ini berlokasi di saluran drainase Sungai Beliung, Kecamatan Pontianak Barat. Lokasi tersebut berhulu di persimpangan Jalan Tebu dan bermuara di Sungai Kapuas. Pengamatan dilakukan saat pasang dan surut, bulan November 2013 dengan tahap penelitian yaitu :

a. Tahap persiapan yaitu berupa pengumpulan referensi dari berbagai literatur yang meliputi jurnal, skripsi dan buku yang berkenaan dengan beban pencemaran dan kualitas air.

b. Tahap pengumpulan data berupa data primer dan data sekunder. Data sekunder yang dikumpulkan dalam penelitian ini berupa data kepadatan penduduk, peta lokasi penelitian, data kualitas air, monografi Kecamatan Pontianak Barat yang didapatkan dari instansiinstansi yang terkait. Sedangkan data primer yang dikumpulkan berupa data dimensi saluran (lebar dan kedalaman), luas penampang basah saluran, kecepatan aliran, debit aliran dan data kualitas air dari hasil pengujian di laboratorium.

c. Tahap Penelitian yaitu menentukan titik lokasi pengamatan (titik sampling air), pengukuran dimensi saluran (lebar dan kedalaman), membuat profil saluran, menghitung luas penampang basah, mengukur dan menghitung kecepatan aliran, menghitung debit aliran dan pengambilan sampel kualitas air.

d. Analisa kualitas air. Proses analisa kualitas air yaitu dengan membandingkan data hasil pengujian di laboratorium dengan baku mutu kualitas air menurut Peraturan Pemerintah No.82 tahun 2001 tentang Pengelolaan Kualitas Air dan Pengendalian Pencemaran Air dalam bentuk tabel dan grafik, melakukan analisis regresi dengan metode kuadrat kecil untuk melihat hubungan konsentrasi pencemar (polutan) terhadap jarak dari setiap lokasi pengamatan dan melakukan perhitungan beban pencemaran yang terdapat pada saluran drainase Sungai Beliung dengan rumus berdasarkan Keputusan Menteri Negara Lingkungan Hidup Nomor 03 Tahun 1998 tentang Baku Mutu Limbah Cair Bagi Kawasan Industri yang berisi penjelasan tentang perhitungan beban pencemaran maksimum untuk menentukan mutu limbah cair yaitu : 
$\mathrm{BP}=\mathrm{Q} \times \mathrm{C}$

Keterangan:

$\mathrm{BP}=$ Beban Pencemaran $(\mathrm{kg} / \mathrm{hari})$

$\mathrm{Q}=$ Debit Sungai $\left(\mathrm{m}^{3} /\right.$ detik)

$\mathrm{C}=$ Konsentrasi Limbah (mg/liter)

\section{HASIL DAN ANALISA}

A. Hasil Perhitungan Luas Penampang Basah Saluran

Perhitungan luas penampang basah saluran dibagi dalam 4 pias atau segmen. Data yang diperlukan dalam perhitungan yaitu data dimensi saluran berupa lebar dan kedalaman yang didapat dari hasil pengukuran di lapangan. Hasil pengukuran dimensi dan perhitungan luas penampang saluran drainase Sungai Beliung dapat dilihat pada Tabel 1 berikut :

Tabel 1 Luas Penampang Basah Saluran Saat Pasang

\begin{tabular}{|c|c|c|c|c|c|c|c|c|c|c|c|c|c|c|c|c|c|}
\hline \multirow{3}{*}{ Lokasi } & \multicolumn{7}{|c|}{ Kedalaman } & \multirow{3}{*}{$\begin{array}{c}\text { Lebar } \\
\text { Pias }\end{array}$} & \multirow{2}{*}{\multicolumn{2}{|c|}{ Jarak }} & \multicolumn{6}{|c|}{ Luas Penampang Basah $\left(\mathrm{m}^{2}\right)$} & \multirow{3}{*}{$\begin{array}{l}\text { Luas } \\
\text { Pias } \\
\text { Total }\end{array}$} \\
\hline & \multicolumn{7}{|c|}{ Pias } & & & & \multicolumn{6}{|c|}{ Pias } & \\
\hline & I & $x_{1}$ & II & III & IV & V & $x_{2}$ & & $\mathrm{x}_{1}$ & $x_{2}$ & $A_{1^{\prime}}$ & $\mathrm{A}_{1}$ & $A_{2}$ & $\mathrm{~A}_{3}$ & $\mathrm{~A}_{4}$ & $\mathrm{~A}_{4^{\prime}}$ & \\
\hline Titik 1 & 0,48 & 0,48 & 0,50 & 0,55 & 0,52 & 0,20 & 0,26 & 1,125 & 0,2 & 0,2 & 0,096 & 0,455 & 0,591 & 0,602 & 0,359 & 0,046 & 2,149 \\
\hline Titik 2 & 0,38 & 0,44 & 0,60 & 0,58 & 0,48 & 0,30 & 0,33 & 1,150 & 0,3 & 0,2 & 0,123 & 0,441 & 0,679 & 0,610 & 0,385 & 0,063 & 2,300 \\
\hline Titik 3 & 0,90 & 0,98 & 1,28 & 1,18 & 0,85 & 0,70 & 0,73 & 1,000 & 0,2 & 0,2 & 0,188 & 0,902 & 1,230 & 1,015 & 0,632 & 0,143 & 4,110 \\
\hline Titik 4 & 0,73 & 0,74 & 0,77 & 0,70 & 0,38 & 0,00 & 0,25 & 1,500 & 0,2 & 1 & 0,147 & 0,978 & 1,103 & 0,810 & 0,158 & 0,127 & 3,323 \\
\hline Titik 5 & 0,70 & 0,87 & 0,98 & 1,30 & 1,10 & 0,68 & 0,94 & 1,625 & 1 & 1 & 0,786 & 0,579 & 1,853 & 1,950 & 0,637 & 0,809 & 6,614 \\
\hline
\end{tabular}

Luas Penampang terbesar di saluran drainase Sungai Beliung berdasarkan Tabel 1 saat kondisi pasang di muara (titik 5) sebesar 6,614 $\mathrm{m}^{2}$. Kondisi ini dipengaruhi oleh kedalaman yang terjadi saat arus pasang terjadi dan lebar saluran yang lebih besar dari titik pengamatan lainnya.

Tabel 2 Luas Penampang Basah Saluran Saat Surut

\begin{tabular}{|c|c|c|c|c|c|c|c|c|c|c|c|c|c|c|c|c|c|}
\hline \multirow{3}{*}{ Lokasi } & \multicolumn{7}{|c|}{ Kedalaman } & \multirow{3}{*}{$\begin{array}{c}\text { Lebar } \\
\text { Pias }\end{array}$} & & & \multicolumn{6}{|c|}{ Luas Penampang $\left(\mathrm{m}^{2}\right)$} & \multirow{3}{*}{$\begin{array}{l}\text { Luas } \\
\text { Pias } \\
\text { Total }\end{array}$} \\
\hline & \multicolumn{7}{|c|}{ Pias } & & \multicolumn{2}{|c|}{ Jarak } & \multicolumn{6}{|c|}{ Pias } & \\
\hline & 1 & $x_{1}$ & II & III & IV & V & $x_{2}$ & & $x_{1}$ & $x_{2}$ & $A_{1^{\prime}}$ & $A_{1}$ & $A_{2}$ & $A_{3}$ & $\mathrm{~A}_{4}$ & $A_{4^{\prime}}$ & \\
\hline Titik 1 & 0,57 & 0,58 & 0,60 & 0,67 & 0,50 & 0,35 & 0,38 & 1,125 & 0,2 & 0,2 & 0,115 & 0,544 & 0,714 & 0,658 & 0,405 & 0,073 & 2,509 \\
\hline Titik 2 & 0,42 & 0,47 & 0,62 & 0,70 & 0,60 & 0,59 & 0,59 & 1,150 & 0,3 & 0,2 & 0,134 & 0,464 & 0,759 & 0,748 & 0,566 & 0,118 & 2,789 \\
\hline Titik 3 & 0,70 & 0,73 & 0,85 & 1,10 & 0,75 & 0,65 & 0,67 & 1,000 & 0,2 & 0,2 & 0,143 & 0,632 & 0,975 & 0,925 & 0,568 & 0,132 & 3,375 \\
\hline Titik 4 & 1,00 & 1,05 & 1,34 & 1,40 & 0,77 & 0,20 & 0,58 & 1,500 & 0,2 & 1 & 0,205 & 1,550 & 2,055 & 1,628 & 0,338 & 0,390 & 6,165 \\
\hline Titik 5 & 1,10 & 1,26 & 1,36 & 1,68 & 1,50 & 0,68 & 1,18 & 1,625 & 1 & 1 & 1,180 & 0,819 & 2,470 & 2,584 & 0,839 & 0,932 & 8,824 \\
\hline
\end{tabular}

Berdasarkan Tabel 2 dapat dilihat bahwa saat surut, di muara (titik 5) juga memiliki luas penampang basah yang lebih luas dibandingkan dengan titik pengamatan lainnya sebesar $8,824 \mathrm{~m}^{2}$. Kondisi ini dipengaruhi oleh dimensi saluran berupa lebar dan kedalaman saluran yang nilainya lebih besar dibandingkan dengan titik pengamatan lainnya.

\section{B. Hasil Pengukuran Kecepatan Aliran}

Pengukuran kecepatan aliran pada saluran drainase Sungai Beliung dilakukan dengan menggunakan pelampung berupa bola kasti yang diikat dengan menggunakan tali sepanjang $10 \mathrm{~m}$ dan dilakukan serempak disemua titik lokasi pengamatan. Pada pengukuran kecepatan aliran dengan pelampung yang dipengaruhi oleh faktor angin harus dibandingkan dengan pengukuran kecepatan aliran yang setara dengan melakukan kalibrasi menggunakan alat current meter. Kecepatan aliran setelah di kalibrasi dapa dilihat pada Tabel 3 berikut :

Tabel 3 Hasil Perhitungan Kecepatan Aliran Setelah di Kalibrasi

\begin{tabular}{|c|c|c|c|c|c|c|c|c|c|c|}
\hline \multirow{3}{*}{ Pias } & \multicolumn{10}{|c|}{$\mathrm{V}_{\text {kalibrasi }}(\mathrm{m} /$ detik$)$} \\
\hline & \multicolumn{5}{|c|}{ Saat Pasang } & \multicolumn{5}{|c|}{ Saat Surut } \\
\hline & Titik 1 & Titik2 & Titik 3 & Titik 4 & Titik 5 & Titik 1 & Titik 2 & Titik 3 & Titik 4 & Titik 5 \\
\hline $0 \mathrm{~L}$ & 0,016 & 0,029 & 0,022 & 0,02 & 0,046 & 0,018 & 0,032 & 0,072 & 0,015 & 0,019 \\
\hline $1 / 4 \mathrm{~L}$ & 0,022 & 0,023 & 0,054 & 0,049 & 0,047 & 0,02 & 0,036 & 0,051 & 0,041 & 0,021 \\
\hline $1 / 2 \mathrm{~L}$ & 0,016 & 0,096 & 0,053 & 0,073 & 0,08 & 0,019 & 0,047 & 0,076 & 0,066 & 0,066 \\
\hline $3 / 4 \mathrm{~L}$ & 0,013 & 0,08 & 0,049 & 0,041 & 0,083 & 0,014 & 0,025 & 0,069 & 0,042 & 0,054 \\
\hline $1 \mathrm{~L}$ & 0,012 & 0,018 & 0,026 & 0,020 & 0,043 & 0,012 & 0,021 & 0,065 & 0,015 & 0,034 \\
\hline Rata-rata & 0,016 & 0,049 & 0,041 & 0,041 & 0,060 & 0,017 & 0,032 & 0,067 & 0,036 & 0,039 \\
\hline
\end{tabular}


Kecepatan aliran rata-rata terbesar pada saluran drainase Sungai Beliung terjadi di muara (titik 5). Hal tersebut dipengaruhi oleh dimensi saluran berupa lebar dan kedalaman pada titik pengamatan 5 yang lebih besar dibandingkan titik pengamatan lainnya dan juga dipengaruhi oleh arus pasang surut dari Sungai Kapuas.

\section{Hasil Perhitungan Debit Aliran}

Debit aliran di saluran drainase Sungai Beliung dilakukan dimasing-masing pias atau segmen. Hasil dari perhitungan debit aliran saluran draianse Sungai Beliung disajikan pada Tabel $\mathbf{4}$ dan Tabel 5 berikut ini :

Tabel 4 Debit Aliran Saluran Drainase Sungai Beliung Saat Pasang

\begin{tabular}{|c|c|c|c|c|c|c|c|c|}
\hline \multirow{2}{*}{ No. } & \multirow{2}{*}{ Lokasi } & \multicolumn{6}{|c|}{ Debit ( $\mathrm{m}^{3} /$ detik) } & \multirow{2}{*}{$Q_{\text {total }}$} \\
\hline & & $\mathrm{Q}_{1^{\prime}}$ & $\mathrm{Q}_{1}$ & $\mathrm{Q}_{2}$ & $\mathrm{Q}_{3}$ & $\mathrm{Q}_{4}$ & $\mathrm{Q}_{4^{\prime}}$ & \\
\hline 1 & Titik 1 & 0,0008 & 0,0087 & 0,0112 & 0,0087 & 0,0046 & 0,0003 & 0,0342 \\
\hline 2 & Titik 2 & 0,0018 & 0,0114 & 0,0404 & 0,0538 & 0,0190 & 0,0006 & 0,1268 \\
\hline 3 & Titik 3 & 0,0020 & 0,0341 & 0,0660 & 0,0522 & 0,0238 & 0,0018 & 0,1800 \\
\hline 4 & Titik 4 & 0,0015 & 0,0337 & 0,0670 & 0,0459 & 0,0048 & 0,0013 & 0,1543 \\
\hline 5 & Titik 5 & 0,0183 & 0,0271 & 0,1175 & 0,1582 & 0,0400 & 0,0174 & 0,3784 \\
\hline \multicolumn{8}{|c|}{ Rata- Rata } & 0,1748 \\
\hline
\end{tabular}

Pada Tabel 4 menunjukkan debit aliran terbesar saat pasang terjadi di muara saluran (titik 5) sebesar $0,3784 \mathrm{~m}^{3} /$ detik. Kondisi ini dipengaruhi oleh masuknya arus pasang dari Sungai Kapuas.

Tabel 5 Debit Aliran Saluran Drainase Sungai Beliung Saat Surut

\begin{tabular}{|c|c|c|c|c|c|c|c|c|}
\hline \multirow{2}{*}{ No. } & \multirow{2}{*}{ Lokasi } & \multicolumn{6}{|c|}{ Debit ( $\mathrm{m}^{3} /$ detik) } & \multirow{2}{*}{$\mathrm{Q}_{\text {total }}$} \\
\hline & & $\mathrm{Q}_{1^{\prime}}$ & $\mathrm{Q}_{1}$ & $\mathrm{Q}_{2}$ & $Q_{3}$ & $\mathrm{Q}_{4}$ & $\mathrm{Q}_{4^{\prime}}$ & \\
\hline 1 & Titik 1 & 0,0010 & 0,0103 & 0,0140 & 0,0110 & 0,0053 & 0,0004 & 0,0421 \\
\hline 2 & Titik 2 & 0,0022 & 0,0159 & 0,0316 & 0,0270 & 0,0132 & 0,0013 & 0,0913 \\
\hline 3 & Titik 3 & 0,0052 & 0,0389 & 0,0617 & 0,0672 & 0,0381 & 0,0043 & 0,2153 \\
\hline 4 & Titik 4 & 0,0016 & 0,0437 & 0,1098 & 0,0877 & 0,0095 & 0,0028 & 0,2551 \\
\hline 5 & Titik 5 & 0,0114 & 0,0164 & 0,1070 & 0,1543 & 0,0367 & 0,0157 & 0,3415 \\
\hline \multicolumn{8}{|c|}{ Rata- Rata } & 0,1891 \\
\hline
\end{tabular}

Pada Tabel 5 juga menunjukkan bahwa saat kondisi surut memiliki debit sebesar $0,3415 \mathrm{~m}^{3} /$ detik, dimana debit tersebut terjadi di muara (titik 5) yang lebih besar daripada titik pengamatan lain, Debit yang terjadi dimasing-masing titik pengamatan pada saluran drainase Sungai Beliung menunjukkan $<5 \mathrm{~m}^{3} / \mathrm{det}$, sehingga berdasarkan (SNI) $6989.57: 2008$ tentang Air dan Air Limbah: Metoda Pengambilan Contoh Air Permukaan yang menyebutkan bahwa apabila sungai dengan debit kurang dari $5 \mathrm{~m}^{3} /$ detik, maka contoh air diambil pada satu titik ditengah sungai pada kedalaman 0,5 kali kedalaman dari permukaan air. Dan debit aliran ratarata terbesar terjadi pada drainase Sungai Beliung saat pasang 0,1748 $\left(\mathrm{m}^{3} /\right.$ detik) lebih lambat daripada saat surut $0,1891\left(\mathrm{~m}^{3} /\right.$ detik).

\section{Data Kualitas Air}

Data kualitas air dari hasil pengujian sampel air pada saluran drainase Sungai Beliung dengan parameter pencemar berdasarkan parameter TSS, DO, BOD dan pH dapat dilihat pada tabel berikut :

Tabel 6 Hasil Pengujian Sampel Kualitas Air Saluran Drainase Sungai Beliung

\begin{tabular}{|c|c|c|c|c|c|c|c|c|c|}
\hline \multirow{3}{*}{ No } & \multirow{3}{*}{ Lokasi } & \multicolumn{8}{|c|}{ Parameter Kualitas Air } \\
\hline & & \multicolumn{4}{|c|}{ Kondisi Pasang } & \multicolumn{4}{|c|}{ Kondisi Surut } \\
\hline & & DO & BOD & TSS & $\mathrm{pH}$ & DO & BOD & TSS & $\mathrm{pH}$ \\
\hline 1 & Titik 1 & 1,18 & 27,11 & 34 & 7,01 & 0,76 & 23,38 & 25 & 6,88 \\
\hline 2 & Titik 2 & 1,18 & 23,72 & 26 & 7,01 & 0,57 & 24,70 & 30 & 6,98 \\
\hline 3 & Titik 3 & 1,61 & 22,54 & 25 & 6,90 & 0,50 & 25,59 & 33 & 6,97 \\
\hline 4 & Titik 4 & 2,54 & 21,69 & 20 & 6,80 & 0,33 & 29,49 & 40 & 6,76 \\
\hline 5 & Titik 5 & 3,38 & 16,61 & 35 & 7,00 & 0,30 & 36,10 & 47 & 6,90 \\
\hline \multicolumn{2}{|c|}{ Rata-rata } & 1,978 & 22,334 & 28 & 6,94 & 0,492 & 27,852 & 35 & 6,90 \\
\hline
\end{tabular}

Sumber : Hasil pengujian langsung di Laboratorium 
Data hasil pengujian sampel air drainase Sungai Beliung dilakukan di Laboratorium Kualitas Tanah, Air dan Lingkungan, Fakultas Teknik, Universitas Tanjungpura denga parameter yang diuji yaitu BOD, DO dan TSS, sedangkan untuk parameter $\mathrm{pH}$ dilakukan secara langsung dilapang (insitu).

\section{E. Analisa Kualitas Air}

a. TSS (Total Suspended Solid)

TSS atau padatan tersuspensi total adalah bahan tersuspensi dengan diameter $>1 \mu \mathrm{m}$ yang tertahan pada saringan miliphore berdiameter pori 0,45 $\mu \mathrm{m}$ sebagai sisa hasil penguapan dan pemanasan pada suhu 103-105ㄷ (Saeni dalam Sasongko, 2006). Hasil pengujian kualitas air untuk parameter TSS dapat dilihat pada Gambar 1 berikut :

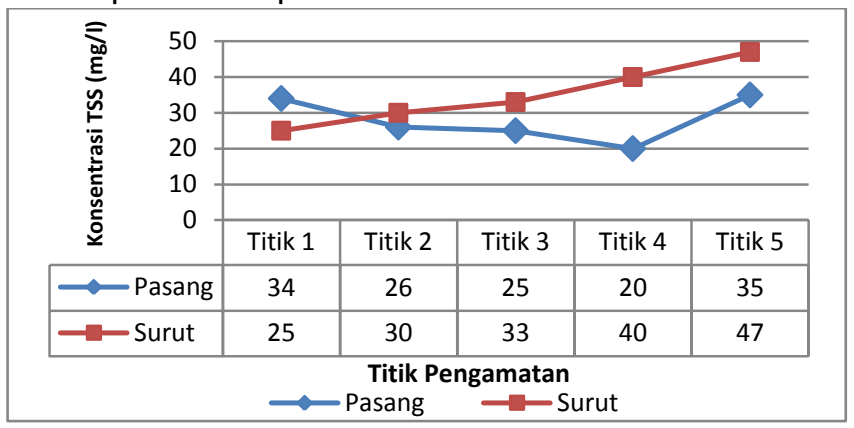

Gambar 1 Sebaran konsentrasi TSS

Pada Gambar 1 saat pasang, konsentrasi TSS tertinggi terjadi di muara (titik 5) yaitu 35 $\mathrm{mg} / \mathrm{l}$ yang dimungkinkan akibat dari buangan sedimen dari PDAM Cabang Jeruju yang ikut terbawa arus pasang serta akibat buangan limbah domestik rumah tangga dari aktifitas mandi, cuci, kakus disekitar kawasan saluran. Pada bagian hulu saluran (titik 1) konsentrasi TSS sebesar $34 \mathrm{mg} / \mathrm{l}$, kondisi tersebut dipengaruhi oleh kondisi saluran yang dangkal akibat debit dan kecepatan aliran yang kecil, sehingga memperlambat peningkatan muka air yang memungkinkan saat sampling dilakukan terdapat lumpur yang ikut terambil. Konsentrasi TSS terendah 20 mg/l terdapat di persimpangan Jalan Tebu dan jalan Kom Yos Soedarso (titik 4) yang diakibatkan oleh pendangkalan saluran oleh buangan limbah domestik rumah tangga dan Pasar Teratai serta akibat banyaknya sampah. Hal tersebut berdampak pada menurunnya kecepatan air dan memberi waktu untuk padatan tersuspensi mengalami pengendapan.

Pada saat surut, konsentrasi TSS terendah $25 \mathrm{mg} / \mathrm{l}$ terdapat di hulu saluran (titik 1). Hal ini diakibatkan oleh pengenceran dan terbawanya partikel tersuspensi oleh arus saat kondisi pasang. Sedangkan untuk konsentrasi TSS tertinggi terdapat di muara (titik 5) $47 \mathrm{mg} / \mathrm{l}$. Peningkatan konsentrasi TSS di muara (titik 5 ) berkaitan dengan aliran air saat surut yang membawa bahan-bahan tersuspensi dari bagian hulu menuju muara saluran. Berdasarkan konsentrasi rata-rata yang terdapat pada Tabel 6 menunjukkan bahwa konsentrasi TSS masih memenuhi baku mutu berdasarkan PP RI No.82 tahun 2001 tentang Pengelolaan Kualitas Air dan Pengendalian Pencemaran Air untuk kelas I yaitu $50 \mathrm{mg} / \mathrm{I}$.

\section{b. BOD ( Biologycal Oxygen Demand)}

Kebutuhan oksigen biologis (BOD) merupakan jumlah oksigen yang diperlukan oleh mikroorganisme aerobik dalam proses penguraian senyawa organik (Effendi, 2003). Berdasarkan hasil pengujian sampel maka untuk konsentrasi BOD dapat dilihat pada Gambar 2 berikut : 


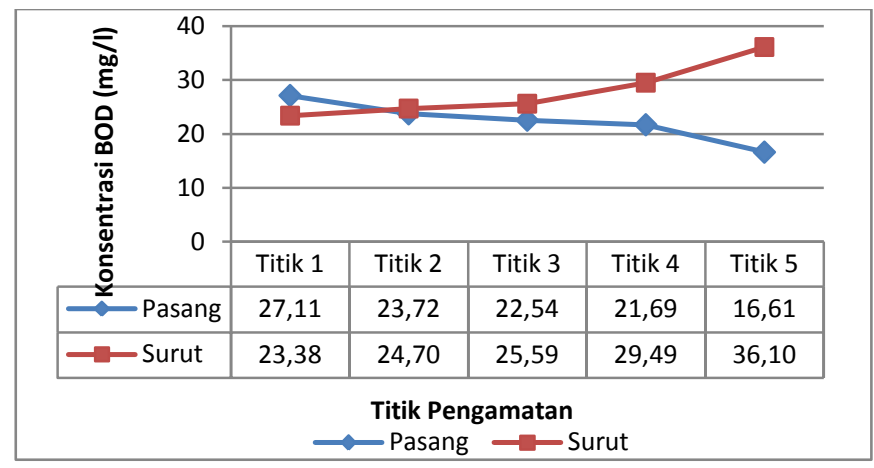

Gambar 2. Sebaran konsentrasi BOD

Gambar 2 menunjukkan saat pasang, konsentrasi BOD terendah 16,61 mg/l terdapat di muara saluran (titik 5) dan konsentrasi BOD tertinggi terdapat di hulu saluran (titik 1). Hal ini dipengaruhi oleh pengenceran yang terjadi saat arus pasang terjadi dan akibat buangan limbah domestik rumah tangga oleh kawasan disekitar saluran drainase Sungai Beliung.

Pada saat surut, dengan arah aliran dari bagian hulu (titik 1) menuju ke muara saluran (titik 5) menunjukkan konsentrasi terendah $23,38 \mathrm{mg} / \mathrm{l}$ terdapat di bagian hulu saluran (titik 1) akibat penambahan massa air saat pasang sehingga konsentrasi BOD terencerkan. Konsentrasi BOD tertinggi $36,10 \mathrm{mg} / \mathrm{I}$ terjadi di muara saluran drainase Sungai Beliung. Berdasarkan konsentrasi rata-rata berdasarkan Tabel 6 menunjukkan bahwa konsentrasi TSS di saluran drainase Sungai Beliung menurut PP RI No.82 tahun 2001 tentang Pengelolaan Kualitas Air dan Pengendalian Pencemaran Air untuk Kelas IV yaitu 12 mg/l hanya dapat diperuntukkan untuk mengairi pertanaman.

\section{c. Do (Dissolved Oxygen)}

Oksigen terlarut berperan penting sebagai indikator kualitas perairan dikarenakan oksigen terlarut berperan dalam proses oksidasi dan reduksi bahan organik dan anorganik. Peranan oksigen terlarut sangat penting untuk membantu mengurangi beban pencemaran secara alami pada suatu perairan. Hasil pengujian konsentrasi oksigen terlarut (DO) pada saluran drainase Sungai Beliung dapat dilihat pada Gambar 3, yaitu :

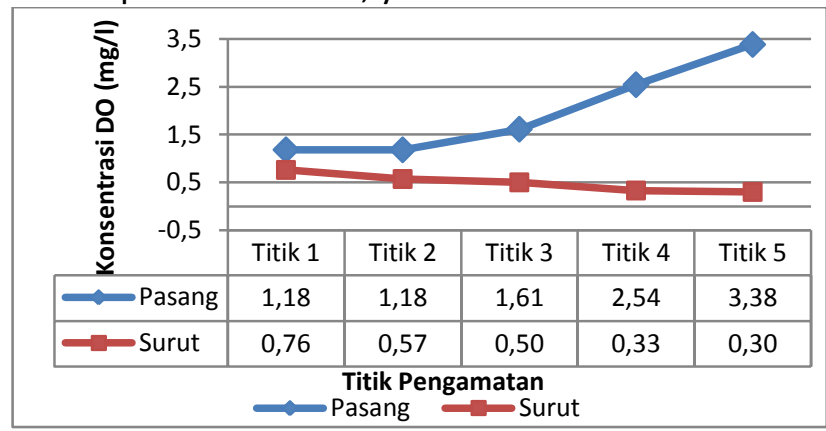

Gambar 3 Sebaran konsentrasi DO

Pada Gambar 3 menunjukkan sebaran oksigen terlarut (DO) saat pasang berkisar antara $1,18-3,38 \mathrm{mg} / \mathrm{l}$ dan saat surut $0,30-0,76 \mathrm{mg} / \mathrm{l}$, dimana saat pasang konsentrasi tertinggi terdapat di muara (titik 5) dan konsentrasi terendah terjadi pada bagian hulu (titik 1), pada saat surut terjadi sebaliknya yaitu konsentrasi tertinggi terjadi pada bagian hulu (titik 1 ) dan konsentrasi terendah terjadi pada muara saluran (titik 5). Adanya masukan bahan-bahan organik yang berasal dari aktifitas disekitar kawasan saluran yang membutuhkan oksigen dalam penguraiannya maupun proses pembusukan bahan organik, respirasi dan reaerasi yang terhambat sehingga menyebabkan kandungan oksigen terlarut (DO) menjadi rendah (Afu, 2005). Konsentrasi rata-rata untuk parameter DO pada Tabel 6 menunjukkan bahwa 
konsentrasi DO memenuhi baku mutu kualitas air yaitu PP RI No.82 tahun 2001 tentang Pengelolaan Kualitas Air dan Pengendalian Pencemaran Air untuk kelas IV yaitu $0 \mathrm{mg} / \mathrm{l}$ yang peruntukannya hanya bisa digunakan untuk mengairi pertanaman. Penurunan konsentrasi oksigen terlarut (DO) mengindikasikan terjadinya pencemaran oleh bahan pencemar organik dari air limbah domestik di daerah pemukiman (Effendi,2003).

\section{d. $\mathrm{pH}$ (Power of Hidrogen)}

$\mathrm{pH}$ merupakan unit pengukuran yang menggambarkan derajat asiditas, alkalinitas sebagai indikator kualitas air. Nilai $\mathrm{pH}$ menunjukkan keseimbangan antara asam dan basa didalam air sehingga bakteri dapat berkembang dan melakukan dekomposisi dengan baik. Hasil pengukuran $\mathrm{pH}$ secara langsung di lapangan (insitu) di saluran drainase Sungai Beliung :

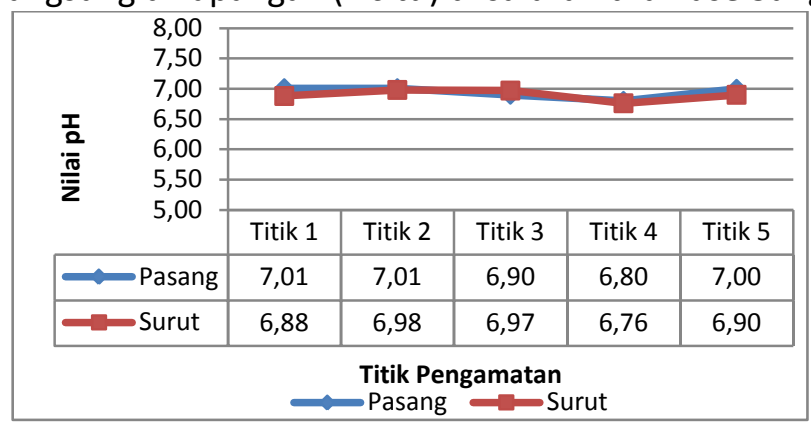

Gambar 4 Sebaran nilai pH

Sebaran nilai pH pada Gambar 4 sebagian besar berada pada $\mathrm{pH}$ normal yang saat pasang berkisar antara 6,80-7,01 dan saat surut berkisar antara 6,76-6,90. Nilai pH rata-rata berdasarkan Tabel 6 menunjukkan bahwa nilai $\mathrm{pH}$ masih memenuhi baku mutu kualitas air untuk Kelas I yaitu 6-9 menurut PP RI No.82 tahun 2001 tentang Pengelolaan Kualitas Air dan Pengendalian Pencemaran Air. Konsentrasi rata-rata untuk nilai $\mathrm{pH}$ yaitu 6,90 juga menunjukkan bahwa $\mathrm{pH}$ mendekati netral $(\mathrm{pH} 7)$.

\section{F. Analisa Hubungan Parameter Pencemar (Polutan) Terhadap Jarak \\ a. Saat Kondisi Pasang}

Pada kondisi pasang, analisa hubungan parameter pencemar (polutan) terhadap jarak dengan metode kuadrat kecil terlihat pada Gambar 5 berikut :

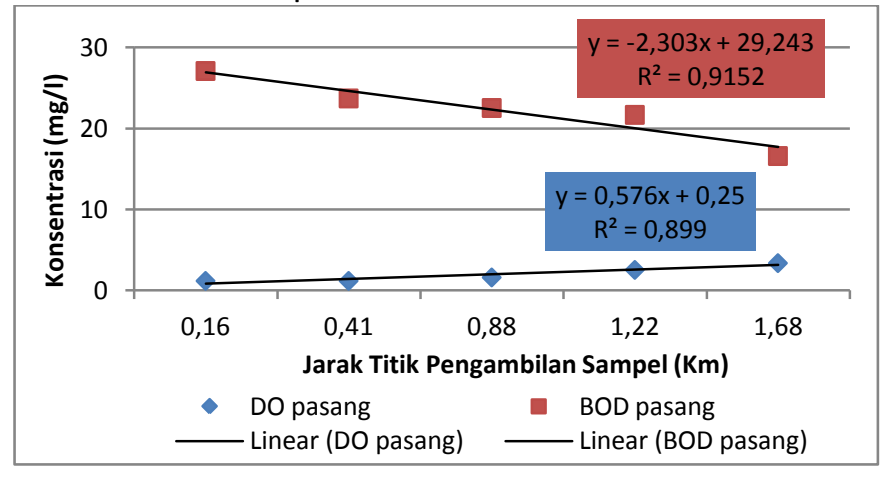

Gambar 5 Hubungan parameter DO dan BOD terhadap Jarak

Analisis regresi untuk parameter DO dan BOD saat kondisi air pasang dapat dilihat pada Gambar 5. Berdasarkan parameter DO persamaan yang terbentuk yaitu $y=0,576 x+0,25$ dengan nilai koefisien determinasi untuk parameter $D O$ yaitu $R^{2}=0,899$. Koefisien determinasi $\left(R^{2}\right)$ menunjukkan bahwa antara variabel independen (konsentrasi DO) terhadap variabel dependen (jarak lokasi pengamatan) mempunyai hubungan yang kuat yaitu sebesar $90 \%$, dan sisanya dipengaruhi oleh variabel lainnya. Sedangkan parameter BOD saat pasang, persamaan 
yang terbentuk yaitu $y=-2,303 x+29,243$ dan menghasilkan koefisien determinasi $R^{2}=0,9152$, menunjukkan bahwa antara variabel independen (konsentrasi BOD) memiliki hubungan yang kuat terhadap variabel dependen (jarak lokasi pengamatan) sebesar $91 \%$ dan sisanya dipengaruhi oleh variabel lainnya.

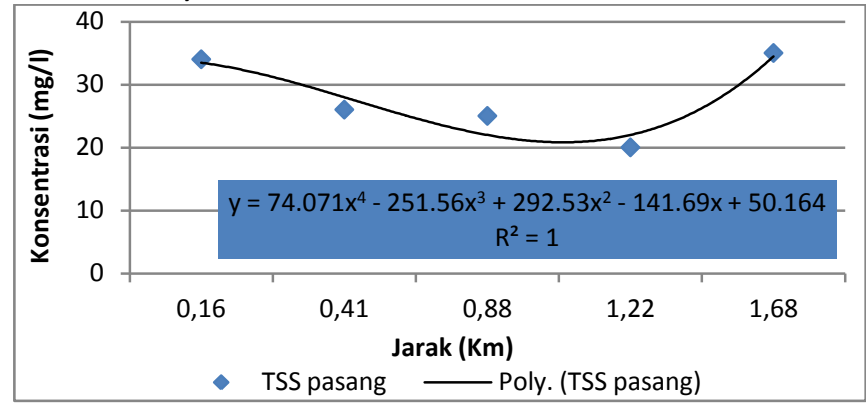

Gambar 6 Hubungan parameter TSS terhadap Jarak

Parameter TSS saat pasang pada Gambar 6 menggunakan regresi non linear dengan bentuk kurva polinomial berpangkat 3 disebabkan oleh sebaran titik data atau diagram pencarnya yang berbentuk lengkungan dan membentuk persamaan $y=74.071 x^{4}-251.56 x^{3}+$ $292.53 x^{2}-141.69 x+50.164$ dengan koefisien determinasi $\left(R^{2}\right)$ adalah 1. Koefisien tersebut menunjukkan bahwa antara variabel independen (konsentrasi TSS) memiliki hubungan yang sangat kuat terhadap variabel dependen (jarak lokasi pengamatan) yaitu sebesar $100 \%$.

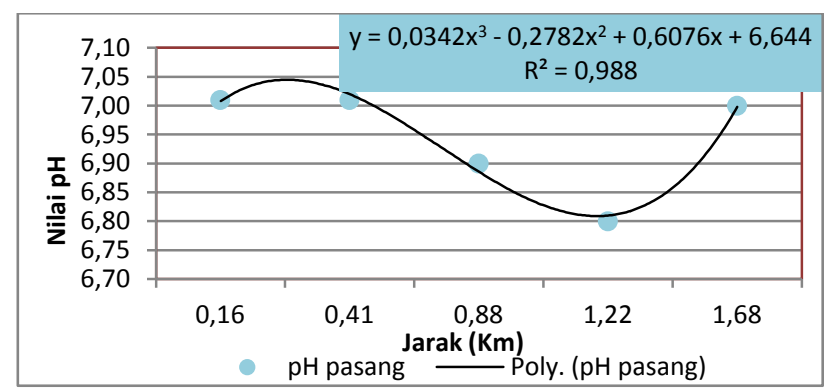

Gambar 7 Hubungan parameter $\mathrm{pH}$ terhadap Jarak

Parameter $\mathrm{pH}$ saat pasang pada Gambar 7, titik-titik data atau diagram pencarnya membentuk lengkungan sehingga menggunakan model kurva polinomial berpangkat 3 dengan persamaan $y=0,0342 x^{3}-0,2782 x^{2}+0,6076 x+6,644$ yang menghasilkan koefisien determinasi $R^{2}=0,988$. Berdasarkan koefisien determinasi $\left(R^{2}\right)$ tersebut menunjukkan bahwa antara variabel independen (konsentrasi $\mathrm{pH}$ ) memiliki hubungan yang sangat kuat terhadap variabel dependen (jarak lokasi pengamatan) yaitu sebesar $99 \%$.

\section{b. Saat Kondisi Surut}

Pada kondisi surut, analisa hubungan parameter pencemar (polutan) terhadap jarak dengan metode kuadrat kecil untuk parameter DO dan BOD dapat dilihat pada gambar berikut:

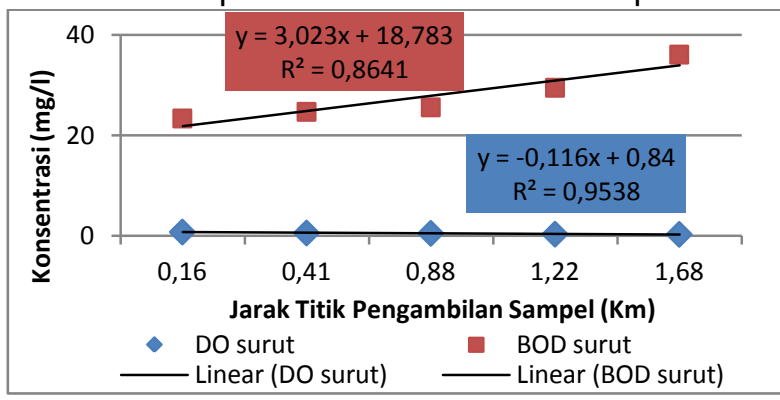

Gambar 8 Hubungan parameter DO dan BOD terhadap Jarak 
Pada Gambar 8, parameter DO yang titik-titik data atau diagram pencarnya berbentuk linear sehingga model kurva untuk parameter DO berbentuk linear dengan persamaan $y=-$ $0,116 x+0,84$ dan koefisien determinasi yaitu $R^{2}=0,9538$. Berdasarkan koefisien determinasi $\left(\mathrm{R}^{2}\right)$ tersebut menunjukkan bahwa antara variabel independen (konsentrasi DO) memiliki hubungan yang sangat kuat terhadap variabel dependen (jarak lokasi pengamatan) yaitu sebesar 95\%. Sedangkan untuk parameter BOD model kurva yang terbentuk yaitu linear dengan persamaan yaitu $y=3,023 x+18,783$ dan koefisien determinasi $R^{2}=0,8641$. Berdasarkan koefisien determinasi $\left(R^{2}\right)$ tersebut dapat dilihat bahwa variabel independen (konsentrasi BOD) memiliki hubungan yang sangat kuat sebesar $86 \%$ terhadap variabel dependen (jarak lokasi pengamatan).

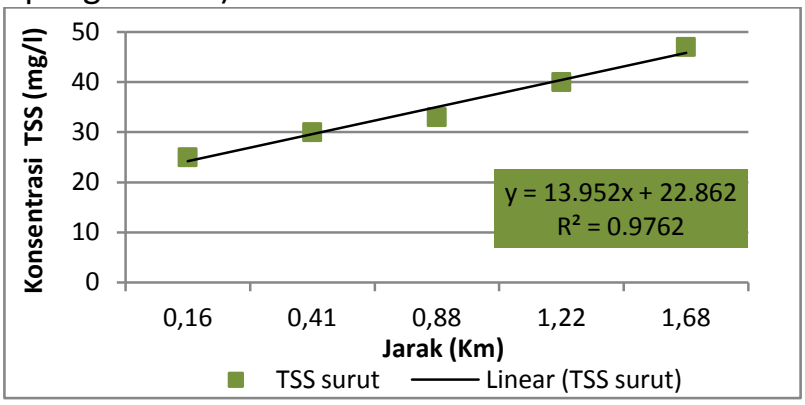

Gambar 9 Hubungan parameter TSS terhadap Jarak

Pada Gambar 9 parameter TSS saat surut membentuk model kurva linear 3 akibat sebaran titik data atau diagram pencarnya yang berbentuk linear dan membentuk persamaan $y=$ $13.952 x+22.862$ dengan koefisien determinasi $R^{2}=0,976$. Koefisien tersebut menunjukkan bahwa antara variabel independen (konsentrasi TSS) memiliki hubungan yang sangat kuat sebesar $98 \%$ terhadap variabel dependen (jarak lokasi pengamatan).

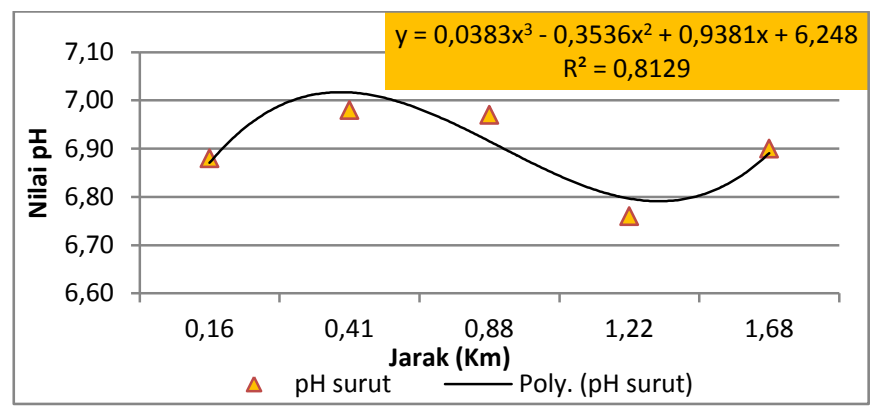

Gambar 10 Hubungan parameter pH terhadap Jarak

Parameter pH pada Gambar $\mathbf{1 0}$ saat surut pada Gambar $\mathbf{5 . 1 0}$ dengan titik-titik data atau diagram pencarnya membentuk lengkungan sehingga menggunakan model kurva polinomial berpangkat 3 dengan persamaan $y=0,0383 x^{3}-0,3536 x^{2}+0,9381 x+6,248$ yang menghasilkan koefisien determinasi $R^{2}=0,8129$. Dan berdasarkan koefisien determinasi $\left(R^{2}\right)$ tersebut menunjukkan bahwa antara variabel independen (konsentrasi $\mathrm{pH}$ ) memiliki hubungan yang sangat kuat terhadap variabel dependen (jarak lokasi pengamatan) yaitu sebesar $81 \%$.

\section{G. Analisa Beban Pencemaran}

Beban pencemaran pada hakikatnya adalah jumlah massa pencemar dalam badan air pada periode tertentu. Beban pencemaran (BP) adalah konsentrasi bahan pencemar (C) dikalikan debit aliran air (Q) yang mengandung bahan pencemar. Sumber - sumber beban pencemar yang masuk ke saluran drainase Sungai Beliung berasal dari kegiatan pemukiman, pasar tradisional, pertokoan seperti rumah makan. Kegiatan tersebut diduga memberikan kontribusi beban pencemaran seperti TSS dan BOD. 
Tabel 7 Hasil Perhitungan Beban Pencemaran

\begin{tabular}{|c|c|c|c|c|c|c|c|}
\hline \multirow{2}{*}{ Parameter } & \multirow{2}{*}{ Kondisi } & \multicolumn{5}{|c|}{ Beban Pencemaran (kg/hari) } & \multirow{2}{*}{$\begin{array}{r}\text { Rata-rata } \\
\text { (kg/hari) }\end{array}$} \\
\hline & & Titik 1 & Titik 2 & Titik 3 & Titik 4 & Titik 5 & \\
\hline \multirow{2}{*}{ TSS } & Pasang & 100,466 & 284,844 & 388,800 & 266,630 & 1144,282 & 437,004 \\
\hline & Surut & 90,936 & 236,650 & 613,863 & 881,626 & 1386,763 & 641,968 \\
\hline \multirow{2}{*}{ BOD } & Pasang & 80,107 & 259,865 & 350,542 & 289,161 & 543,043 & 304,544 \\
\hline & Surut & 85,043 & 192,475 & 476,023 & 649,978 & 1065,152 & 493,734 \\
\hline
\end{tabular}

Hasil perhitungan beban pencemaran dari parameter TSS dan BOD saat pasang dan surut menunjukkan bahwa beban pencemaran tertinggi terdapat pada muara saluran (titik 5). Hal tersebut terkait adanya kegiatan pengolahan air di PDAM cabang Jeruju yang membuang sedimen hasil pengolahannya ke Sungai Kapuas. Selain itu, adanya masyarakat yang bermukim disekitar muara saluran juga turut menyumbangkan beban pencemaran dari limbah domestik yang dibuang secara langsung ke saluran. Sedangkan untuk rata-rata beban pencemaran dari padatan tersuspensi (TSS) dan BOD pada saat pasang lebih sedikit daripada saat surut. Seperti halnya pada penelitian Rafni (2004) yang menyatakan bahwa pada saat pasang beban pencemaran relatif menurun, dimana nilai beban tersebut diduga disebabkan oleh adanya proses penganceran dan pembilasan yang terjadi akibat adanya pasang surut serta proses degradasi. Selain itu, pengaruh pasang yang lebih dominan dibandingkan pada saat surut mengakibatkan proses pengenceran dan pembilasan diperairan tersebut berjalan dengan baik.

\section{KESIMPULAN}

Berdasarkan penelitian yang telah dilakukan, maka dapat disimpulkan :

a. Beban pencemaran tertinggi di muara saluran (titik 5), berdasarkan parameter TSS saat pasang $1144 \mathrm{~kg} / \mathrm{hari}$ dan saat surut $1387 \mathrm{~kg} / \mathrm{hari}$. Sedangkan beban pencemaran berdasarkan parameter BOD saat pasang $543 \mathrm{~kg} / \mathrm{hari}$ dan saat surut $1065 \mathrm{~kg} /$ hari. Ratarata beban pencemaran saat surut lebih tinggi dari pada saat pasang, dimana rata-rata beban pencemaran berdasarkan parameter TSS saat surut $642 \mathrm{~kg} /$ hari dan saat pasang 437 $\mathrm{kg} / \mathrm{hari}$ dan rata-rata beban pencemaran berdasarkan parameter BOD saat surut 494 $\mathrm{kg} / \mathrm{hari}$ dan saat pasang $304 \mathrm{~kg} / \mathrm{hari}$.

b. Kualitas air yang diwakili oleh parameter TSS, BOD, DO dan pH hanya memenuhi kualitas air Kelas IV berdasarkan Peraturan Pemerintah Republik Indonesia No.82 tahun 2001 tentang Pengelolaan Kualitas Air dan Pengendalian Pencemaran Air yang peruntukannya untuk mengairi pertanaman. Hal tersebut menunjukkan bahwa air di saluran drainase Sungai Beliung tidak dapat digunakan untuk kebutuhan sehari-hari seperti air minum maupun aktifitas mandi,cuci,kakus (MCK) tanpa pengolahan terlebih dahulu.

\section{Ucapan Terima Kasih}

Penulis mengucapkan terima kasih kepada kedua orang tua yang telah memberikan dukungan secara moril dan materil. Terima kasih juga kepada Bapak Ir. Nashrullah Chatib.,MT dan Bapak Robby Irsan ST.,M.Si selaku dosen pembimbing dalam penelitian ini serta tidak lupa pula kepada teman-teman angkatan 2009 Fakultas Teknik UNTAN yang banyak membantu dalam penyelesaian skripsi ini.

\section{Referensi}

Direktorat Jenderal Cipta Karya. 2012, Materi Bidang Drainase Desimilasi dan Sosialisasi Keteknikan Bidang PLP. Jakarta : Kementrian Pekerjaan Umum.

Effendi, Hefni. 2003. Telaah Kualitas Air. Yogyakarta : Kanisius

Fardiaz, Srikandi. 1992. Polusi Air dan Udara. Yogyakarta : Kanisius

Rafni, Rita. 2004. Kapasitas Asimilasi Beban Pencemar di Perairan Teluk Jobokuto, Kabupaten Jepara Jawa Tengah. Bogor : Institut Pertanian Bogor.

Suripin.2004. Sistem Drainase Perkotaan yang Berkelanjutan. Yogyakarta : Penerbit Andi.

Wesli. 2008. Drainase Perkotaan.Yogyakarta : Graha Ilmu 